\title{
A new approach to produce succinic acid through a co-culture system
}

Alaa Salma ${ }^{1}$, Rawa Abdallah ${ }^{2}$, Florence Fourcade ${ }^{1}$, Abdeltif Amrane $^{1}$ \& Hayet Djelal ${ }^{3 *}$

${ }^{1}$ Univ Rennes, Ecole Nationale Supérieure de Chimie de Rennes, CNRS, ISCR, UMR6226, F3500 Rennes, France

${ }^{2}$ Universite Libanaise, EDST, Centre Azm pour la Recherche en Biotechnologie et ses Applications, Rue El Mitein, LBA3B Tripoli, Lebanon

${ }^{3}$ UniLaSalle-Ecole des Métiers de l'Environnement, Avenue Robert Schuman, Campus de Ker Lann, 35170 Rennes, France

*Corresponding author: Unilasalle-Ecole des Métiers de l'Environnement, Campus de Ker Lann, 35170 Bruz,

E-mail addresses: hayet.djelal@unilasalle.fr (H. Djelal) 


\section{Abstract}

Microorganisms can produce a wide range of bio-based chemicals that can be used in various industrial applications as molecules of interest. In the present work, an analysis of the power production by pure culture, co-culture, and sequential culture was performed. In this study, both the mono-culture and the co-culture strategies of Actinobacillus succinogenes with Saccharomyces cerevisiae as carbon sources to produce succinic acid using glucose and fructose were examined. The cultures were performed in batch mode and a great attention was paid to the co-culture system to improve the biosynthetic pathway between $A$. succinogenes and S. cerevisiae by combining these two strains in a single fermentation process. Under microaerobic and anaerobic conditions, the process was characterized in terms of sugars concentration, cell density, metabolites, yield (mol-C products/ mol-C sugars), the temperature conditions for productivity and $\mathrm{pH}$. The results showed that the process could consume glucose and fructose and could adapt to different concentrations of the two sugars more quickly than by a single organism and the best results were obtained in a sequential co-culture recording 0.27 mol L $\mathrm{L}^{-1}$ of succinic acid concentration and a volumetric productivity of $0.3 \mathrm{~g} \mathrm{~L}^{-1} \mathrm{~h}^{-1}$. Under the investigated operating conditions, the combination of these two strains in a single reactor produced a significant amount of succinic acid (0.70 mol-C SA/ mol-C substrates). A simultaneous and sequential co-culture strategy can be a powerful new approach in the field of bio-based chemical production.

Key-words: Fermentation; Co-culture; sequential culture; bio-based chemicals; Succinic acid. 


\section{Introduction}

An interest in the bio-based chemicals production from sugars has strongly increased in the last decade, as these sugar-derived products can potentially replace oil-derived chemicals such as succinic acid [1]. Traditionally, succinic acid (SA) is derived from fossil sources via the hydrogenation of maleic anhydride and considered as a key platform chemical as it is used in the production of a wide range of products, from pharmaceuticals to green solvents, fibers and bioplastics [2]. There is a tremendous opportunity for SA biosynthesis: indeed bio-based SA is interesting and advantageous because its production does not contribute to the accumulation of carbon dioxide $\left(\mathrm{CO}_{2}\right)$ into the environment and can thus be considered as a "green" chemical $[3,4]$. SA fermentation is relatively well studied thanks to an array of microorganisms and under different conditions $[5,6]$. The conventional production of bio-SA involves anaerobic bacterial fermentation of pure or mixed sugars with the addition of $\mathrm{CO}_{2}$ sources, such as Actinobacillus succinogenes $[7,8]$. Previous studies showed that the production of SA could be raised by controlling the supply of $\mathrm{CO}_{2}$ in the fermentation media, which can significantly increase the product cost [9]. A. succinogenes can be used but require an anaerobic environment (nitrogen bubbling), as well as dissolved $\mathrm{CO}_{2}$ in the fermentation broth, such as $\mathrm{MgCO}_{3}$, which definitely controls the metabolic flux of carbon. Also the activity of enzymes including phosphoenolpyruvate carboxykinase (PEPCK) represent crucial steps for succinic acid bioproduction by succinate-producing bacteria [10]. To create a potential method, it is important to improve its efficiency and sustainability. To do so, two key tools were used in various fields of study to improve the process output : more precisely to optimize the operating conditions and to manipulate/steer the microbial community, which requires the improvement of the existing knowledge on the relationship between the microbial community structure and operational conditions [11]. Several studies related to the impact on SA outputs of the operating conditions, in different variations and/or combinations, such as the $\mathrm{pH}$ [12], temperature [13], 
culture conditions [14] and the standardised or various types of substrates [15] were reported, evaluated and investigated. Apart from the effects of the operating parameters, some studies focused on metabolic pathways such as turn on/off gene pathways [16]. Most previous studies focused on finding correlations between the operating parameters and the SA production $[4,7$, $10,13,15]$; however only a few investigated the relationships with the microbial community in the same environment [17]. Different processes have been adopted for SA fermentation: batch fermentation, fed-batch fermentation, free-cell continuous fermentation, continuous fermentation with immobilized cells $[5,7,18]$. Although most products in industrial biotechnology are produced by only one bacterium, mixed culture fermentation has also frequently been employed [17, 19]. Mixed culture biotechnology (MCB) could become an attractive alternative to traditional pure culture-based biotechnology enabling the production of a narrow spectrum of chemicals and/or bioenergy issued from pure or mixed substrates [17, 20]. Mixed-culture fermentations contain inoculum always consisting of the mixture of two or more known or unknown species [21]. They can be the mixed culture of organisms belonging to one microbial group, like bacteria, or they can consist of the mixture of fungi and bacteria organisms or fungi and yeasts organisms or other combinations whose components are quite unrelated $[19,22]$. Generally, co-culture was defined as anaerobic or aerobic incubation of different specified microbial strains under aseptic conditions and it seems to be advantageous compared to pure culture fermentation due to the potential for synergistic utilization of the metabolic pathways of all involved microorganisms in a co-culture system [23]. Thus, it may result in increased yield, improved product qualities, and more efficient substrate utilization. It has been widely used in the production of bio-chemicals, biofuel, biopolymers, and enzymes [24].The main motivation behind employing co-culture in this work is to examine the interactions between microorganisms and to develop new cell approach techniques to produce platform molecules [25]. The microorganisms subsequently consuming sugars must have lower 
productivities for the generation of a product than the organisms simultaneously consuming sugars [26].

A. succinogenes was used as succinic acid producer in several studies due to its simple medium requirements for strain culture and relatively high product yield $[8,10,27]$. However, in the context of a large-scale succinic acid production, the use of both $\mathrm{MgCO}_{3}$ and $\mathrm{N}_{2}$ gases can become prohibitively expensive due to their high prices, and thus, considered as shortcoming in SA production on high-scale. To overcome these limitations, we suggest a new strategy for an eco-efficient SA production based on a partnership between yeast producing $\mathrm{CO}_{2}$, Saccharomyces cerevisiae, with SA producing bacteria, A. succinogenes. In this system, $S$. cerevisiae digested glucose to produce ethanol, glycerol and $\mathrm{CO}_{2}$ as a carbon source; the $\mathrm{CO}_{2}$ produced by yeast respiration during fermentation of sugars could be fixed by A. succinogenes. Although, A. succinogenes can use glycerol as a substrate and in return produce SA. Thus, $S$. cerevisiae is employed in SA/ethanol production and the two species could form an ecoefficient co-culture system, which performed "better together" for biofuel and biochemical generation. It can be a reliable, cheap, easy to manage and sustainable alternative strategy that could effectively replace the addition of $\mathrm{MgCO}_{3}$ and the $\mathrm{N}_{2}$ sparging.

The concept focuses on the possibility of the easy "design" of a co-culture approach, in simultaneous and sequential cultures, that could be a bridge between feedstocks and a bio-based production. At this point, we start creating a synthetic co-culture of $A$. succinogenes (DSM 22257) and S. cerevisiae (CLIB 95) in order to produce SA by an efficient joint use of sugar mixtures. In this report, the results of this new method producing direct SA from substrates are recorded and Batch data of viability, residual sugars, yield, productivity and SA concentration using the fermentation process of $A$. succinogenes $-S$. cerevisiae co-cultures are discussed. 


\section{Materials and Methods}

\section{Microorganisms and the inoculum preparation}

The Deutsche Sammlung von Mikroorganismen und Zellkulturen (Institute DSMZ-German Collection of Microorganisms and Cell Cultures) issued A. succinogenes (DSM 22257) and the CIRM (Centre National de Ressources Microbiennes, France) provided yeast, S. cerevisiae

\section{CLIB 95.}

The Bacterial inoculum was prepared as follows: The bacterium was suspended in a Trypton Soya Broth (TSB) and preserved on Tryptic Soya Agar (TSA) plates and slants. Cells were incubated at $37^{\circ} \mathrm{C}$ for $24-48$ hours in an incubator (VWR® INCU- Line), which was the time required for the microorganism to reach the exponential growth phase. As for yeast species, Saccharomyces cerevisiae were maintained at $4{ }^{\circ} \mathrm{C}$ on a Sabouraud glucose agar $4 \%$ slant containing ( $\left.\mathrm{g} \mathrm{L}^{-1}\right): 40 \mathrm{~g}$ glucose, $10 \mathrm{~g}$ peptones, $15 \mathrm{~g}$ of agar; then cells were incubated at $28{ }^{\circ} \mathrm{C}$ in the incubator for 24 hours. In order to generate bacterium and yeast inocula, culture suspensions were transferred to 50-mL centrifuge tubes, resuspended in KCL $150 \mathrm{mM}$ and incubated in an incubator shaker (New Brunswick, INNOVA 40, NJ, USA) at $37{ }^{\circ} \mathrm{C}, 150 \mathrm{rpm}$ for 24 and 48 hours for yeast and bacteria respectively.

As for the co-culture, cells were aseptically centrifuged $\left(1800 \mathrm{~g}, 4^{\circ} \mathrm{C}\right.$ and $\left.5 \mathrm{~min}\right)$ in a centrifugation (Thermo-Fisher, scientific, HERAEUS Megafuge 16R), suspended in $10 \mathrm{~mL}$ $\mathrm{KCl}(150 \mathrm{mM})$ at the end of the incubation period. For the preparation of the inoculum, $2 \mathrm{~mL}$ of suspended culture cells were transferred into $250 \mathrm{~mL}$ Anaerobic bottles containing $200 \mathrm{~mL}$ of culture medium. Depending on the experimental set-up, the populations were mixed at a different $\% \mathrm{v} / \mathrm{v}$ ratio of bacterial-yeast populations, respectively $(0.25 ; 0.75),(0.5 ; 0.75)$, $(0.75 ; 0.25)$, with an equal starting optical density. Co-cultures could potentially be carried out in a $200 \mathrm{~mL}$ volume range at $37^{\circ} \mathrm{C}$ and $150 \mathrm{rpm}$ for 48 hours and population densities were 
measured at $660 \mathrm{~nm}$. Cells from co-culture were centrifuged and the suspension obtained in 10 $\mathrm{mL}$ of $\mathrm{KCl} 150 \mathrm{mM}$ was used for inoculation.

Fermentation media contained carbon and nutrient sources (per liter): $32 \mathrm{~g}$ glucose, $32 \mathrm{~g}$ fructose and $0.53 \mathrm{~g} \mathrm{NH}_{4} \mathrm{Cl}$, and minor components including inorganic salts, buffers and cofactors (per liter): $3 \mathrm{~g} \mathrm{~K}_{2} \mathrm{HPO}_{4}, 3 \mathrm{~g} \mathrm{KH}_{2} \mathrm{PO}_{4}, 1.25 \mathrm{~g} \mathrm{NaCl}, 0.3 \mathrm{~g} \mathrm{MgCl}_{2} \cdot 6 \mathrm{H}_{2} \mathrm{O}, 0.3 \mathrm{~g}$ $\mathrm{CaCl}_{2} \cdot 2 \mathrm{H}_{2} \mathrm{O}, \mathrm{NaH}_{2} \mathrm{PO}_{4}, \mathrm{Na}_{2} \mathrm{HPO}_{4}$. Fermentation media were sterilized by filtration on a 0.22 $\mu \mathrm{m}$ sterile membrane filter (Sartorius), when setting up the fermenters.

\section{Fermentation experiments}

Fermentations were achieved under optimized conditions at $37^{\circ} \mathrm{C}$ in $200 \mathrm{~mL}$ of synthetic media in anaerobic conditions, by inoculating different biomass concentrations of $A$. succinogenes and S. cerevisiae. The inoculations were performed in the following way: 1) Co-culture (the inoculation of $A$. succinogenes with $S$. cerevisiae simultaneously); 2) Sequential inoculations of $S$. cerevisiae, followed by the inoculation of $A$. succinogenes after 48 hours, were run in a 3L-capacity benchtop reactor with a volume of $1800 \mathrm{~mL}$. A. succinogenes and S. cerevisiae pure cultures fermentations were also run as controls. As mentioned previously, both strains were pre-cultured and the inoculated volumes were calculated according to the final volume present in anaerobic bottles. A fermentation temperature of $37^{\circ} \mathrm{C}$ and stirring speed of $150 \mathrm{rpm}$ were maintained throughout the incubation period. During the fermentations, samples were aseptically drawn $(5 \mathrm{~mL})$ from the broth at various time points $-24,48,72$ and 94 - in order to follow up the microbial growth, sugar consumption and the production or uptake of acids (e.g., succinic, formic, acetic, and lactic acid) and other compounds (e.g., ethanol). 


\section{Analyses}

Cell growth was detected by measuring the optical density (OD) of the sample at 660nm $(\lambda 660)$ using a UV-VIS spectrophotometer (PRIM SECOMAM, Milton Roy, Ivyland, PA, USA). OD measurements were carried out immediately after sampling by using $4 \mathrm{ml}$ plastic cuvettes, and dionized water was used as blank (zero absorbance). The sample was homogenized and then analyzed. Samples were collected from the broth every 24 hour and centrifuged at $1800 \mathrm{~g}$ for 5 min. The supernatants were then transferred to $15 \mathrm{~mL}$ tubes and were analyzed according to previously published methods [28]. Briefly, sugars (glucose, and fructose), organic acids (succinic, acetic acid,) and others were detected by HPLC using BioRad HPX-87H column at $45{ }^{\circ} \mathrm{C}$ with $0.01 \mathrm{~N} \mathrm{H}_{2} \mathrm{SO}_{4}$ mobile phases flowing at $0.7 \mathrm{~mL} / \mathrm{min}$.

\section{Statistical analyses}

The analysis of data was carried out thanks to an ESP script (EXCEL software program 2016) using T-test $(\mathrm{p}<0.05)$ and was reported as a mean and standard deviation.

\section{Results}

Comparative analysis of the production of a pure culture of $A$. succinogenes and $S$. cerevisiae in $250 \mathrm{~mL}$ batch bottles

In this experiment, two cultures were inoculated as pure cultures in separate batch bottles. The readings were carried out for two days. Table 1 shows the potential and current comparison between the $A$. succinogenes and $S$. cerevisiae pure cultures. During fermentation, $A$. succinogenes produced SA under anaerobic conditions and no other acids were produced, in particular lactic acid. This result shows the capacity of $A$. succinogenes to ferment glucose and fructose that are used as carbon sources to synthesize and produce succinic acid. [29] report that A. succinogenes prefer consuming glucose, but it can also metabolize glycerol (by-products 
of the ethanol fermentation process naturally produced by $S$. cerevisiae). Fermentation performances differ for each and every microbiome. Likewise, S. cerevisiae produce glycerol, ethanol and $\mathrm{CO}_{2}$ in the fermentation media. About $0.2 \mathrm{~mol} \mathrm{~L}^{-1}$ of $\mathrm{SA}$ was produced using $A$. succinogenes after 48 hours, respectively corresponding to a yield of 0.6 mol-C SA/mol-C substrate and $0.49 \mathrm{~g} \mathrm{~L}^{-1} \mathrm{~h}^{-1}$ productivity. However, when $S$. cerevisiae was cultivated, ethanol and glycerol were the metabolites produced by this microorganism recording a value of about $0.07 \mathrm{~mol} \mathrm{~L}^{-1}$ for each metabolite. Their ability to grow and undergo metabolic processes in both aerobic and anaerobic conditions are remarkable characteristics of S. cerevisiae. In aerobic conditions, S. cerevisiae performs cellular respiration through the oxidative phosphorylation of pyruvate, producing $\mathrm{CO}_{2}$. In anaerobic conditions, $S$. cerevisiae turns fermentative metabolism into ethanol and carbon dioxide (as the primary fermentation metabolites) as the cells strive to produce energy and regenerate the $\mathrm{NAD}^{+}$coenzyme [30]. Henceforth, A. succinogenes and $S$. cerevisiae were chosen for the fermentation study as co-cultures.

\section{Effect of the inoculation mode on the microbial growth during the fermentation in 250} mL bottles using a \% ratio of ( 0.5 A. succinogenes; 0.5 S. cerevisiae $)$

Fig 1 reveals the microbial evolution $\left(\mathrm{OD}_{660 \mathrm{~nm}}\right)$ of pure cultures and co-cultures with a \% volume ratio of $(0.5 ; 0.5)$ corresponding to 0.04 of $A$. succinogenes and S. cerevisiae starter optical density in microaerobic and anaerobic conditions (Fig 1 a- and b-, respectively). A significant difference was found in the cell density between the co-cultures and the $A$. succinogenes single culture $(\mathrm{p}<0.05)$ during fermentation. The results indicate that the growth of A. succinogenes was not limited by S. cerevisiae regardless of the combination. On the contrary, these were A. succinogenes that decreased the growth of S. cerevisiae without causing their deaths. The microaerobic co-cultures showed a slight decrease in their evolution during 
fermentation in comparison with the $S$. cerevisiae pure culture control. The evolution difference between the co-culture and the $S$. cerevisiae single culture was not obvious, however, and the cell density in S. cerevisiae was more than the one obtained by the co-culture (Fig 1-a). During the anaerobic fermentation, when both strains were simultaneously inoculated together (Fig. 1 b), the co-cultures persisted for the first 3 days with an OD higher than the one obtained from the monoculture of A. succinogenes, then reducing gradually. Sequential cultures attained and retained optical cell densities more important than the ones achieved in the pure culture and in anaerobic co-cultures at the end of the fermentation time. When A. succinogenes was sequentially supplied as a starter after 48 hours, the $S$. cerevisiae became the dominant species throughout the fermentation process in comparison with A. succinogenes.

\section{Effect of $\mathrm{MgCO}_{3}$ on a simultaneous co-culture fermentation}

To evaluate the effect of $\mathrm{MgCO}_{3}$ in the fermentation, a simultaneous co-culture was inoculated with a \% ratio of $(0.5 ; 0.5)$ corresponding to 0.04 of $A$. succinogenes and S. cerevisiae starter optical density. Fig 2 a- and b represent the sugars and the evolutions of the products profiles with or without the addition of $\mathrm{MgCO}_{3}$.

As shown in Fig. 2, the use of sugar was not significantly different in (a) and (b). The glucose and fructose levels decreased significantly in the microaerobic co-culture fermentation: more than $91 \%$ was consumed. These data confirmed that the co-culture system can consume both glucose and fructose, whereas ethanol and glycerol were produced - about $0.1 \mathrm{~mol} \mathrm{~L}^{-1}$ and 0.06 mol L ${ }^{-1}$ respectively - and the produced amounts were nearly similar irrespective of the presence of the $\mathrm{MgCO}_{3}$ supplement. SA production was monitored and found to remain negligible throughout the culture in the absence of $\mathrm{MgCO}_{3}$ (Fig 2-a); while 0.04 mol L-1 SA was produced in the presence of $\mathrm{MgCO}_{3}$ (Fig 2-b), corresponding to a yield of $0.1 \mathrm{~mol}-\mathrm{C} \mathrm{SA} / \mathrm{mol}-\mathrm{C}$ substrates and a production of $0.05 \mathrm{~g} \mathrm{~L}^{-1} \mathrm{~h}^{-1}$. It confirms the need for a mineral carbon source. The 
evolution of $\mathrm{CO}_{2}$ depends on the extent of sugars being metabolized by $S$. cerevisiae and used by A. succinogenes. The divergence in the SA concentration observed between its two values could be attributed to the release of $\mathrm{CO}_{2}$ by $S$. cerevisiae, indicating the stimulation of a $\mathrm{CO}_{2}$ production and yeast metabolism during the stage of fermentation. Therefore, the assimilation of the inorganic carbon source showed the potential of the two strains to be used as co-cultures in a microaerobic fermentation to increase the persistence of $\mathrm{CO}_{2}$ and to improve the $\mathrm{SA}$ production process quality (supplementary table $\mathrm{S} 1$ ). The $\mathrm{CO}_{2}$ production in the co-cultures correlates with the transcriptional up-regulation of the glucose fermentation pathway genes from S. cerevisiae [31] and the consumption rates correlate to the fixation of $\mathrm{CO}_{2}$ to produce SA from A. succinogenes [32]. The stimulatory effects that occur during fermentation correspond to the direct response of $S$. cerevisiae and A. succinogenes to the presence of each other.

Influence of the ratio of S. cerevisiae-A. succinogenes on the performance of simultaneous microaerobic and anaerobic co-culture during fermentation.

The variation of the biomass ratio in the culture medium may significantly affect the values of the fermentation parameters calculated from the measured concentrations of the substrates and/or products. As shown in the above results, SA could be produced by the co-culture of $S$. cerevisiae and A. succinogenes. To evaluate the co-culture fermentation on the SA production, the co-culture of S. cerevisiae and A. succinogenes were provided to the media at different $\%$ $\mathrm{v} / \mathrm{v}$ ratios $(0.25 ; 0.75: 0.75 ; 0.25)$ corresponding to $(0.04 ; 0.06)$ starter optical density and compared to their mono-cultures. Fig. 3 reveals the differences between the concentrations of metabolites in the fermentation with a different biomass ratio in the co-culture without $\mathrm{MgCO}_{3}$. To investigate the impact of biomass ratios on the performance of fermentation, the metabolites in the culture were compared in microaerobic and anaerobic conditions. For both inoculation 
ratios, the SA production from co-cultures fermentations was only observed in anaerobic conditions and was significantly reduced in microaerobic conditions (see fig $3 \mathrm{a}$, and b).

The maximum value of the SA was obtained in anaerobic conditions from a co-culture \% ratio of $(0.25 ; 0.75)$ of S. cerevisiae- A. succinogenes, $0.23 \mathrm{~mol} \mathrm{~L}^{-1}$ (Fig 3-a); while only $0.03 \mathrm{~mol} \mathrm{~L}$

${ }^{1} \mathrm{SA}$ was produced in microaerobic conditions regardless the biomass ratio corresponding to $0.28 \mathrm{~g} \mathrm{~L}^{-1} \mathrm{~h}^{-1}$ and $0.037 \mathrm{~g} \mathrm{~L}^{-1} \mathrm{~h}^{-1}$, respectively of SA productivity, wherein the fermentation activity of the A. succinogenes strain was limited. Regarding the formation of ethanol, there was a substantial reduction in the ethanol concentration from all the co-cultures at the end of the fermentation time (96 hours) compared to that obtained from a co-culture \% ratio of $(0.75$; 0.25) of S. cerevisiae-A. succinogenes. The variation of the ratio of co-culture shows that the total production of $(0.75 ; 0.25)$ of $S$. cerevisiae- $A$. succinogenes was obviously slower than the one obtained by $(0.25 ; 0.75)$ of $S$. cerevisiae- A. succinogenes. However, results show that the highest value of SA was obtained in the anaerobic mono-culture of A. succinogenes. Biomass concentrations deduced from Dry cell weight (DCW) decreased at the end of the fermentation (96 hours) for all the co-cultures and recorded a maximum value of $0.40 \mathrm{~g} \mathrm{~L}^{-1}, 0.49 \mathrm{~g} \mathrm{~L}^{-1}$ for figure $3-a$, and $-b$, respectively, as a result of the increased formation of product and substrate limitations which provoked a drastic decrease of the microbial biomass.

\section{Influence of the inoculation mode}

To investigate the effect of the inoculation mode on the co-culture fermentation, the two strains were inoculated simultaneously and/or in different orders from an optical cell density of 0.03 starter strains (table 2) with a constant culture time for all the experiments. In the microaerobic co-cultures, significant amounts of SA were produced; while no production was observed in the pure culture of each strain. In addition, the comparison of the simultaneous and the sequential co-cultures showed a slightly higher amount in the case of the sequential co-culture. 
As mentioned above, SA was produced by A. succinogenes in anaerobic fermentation while ethanol and glycerol were produced by $S$. cerevisiae. In all the experiments, the co-culture of A. succinogenes and S. cerevisiae produced more metabolites than in pure cultures. The SA obtained from the sequential 48-hour cultures revealed a remaining in sugar content, while it turns to fall in the co-culture fermentations profile that were analogous in order of metabolites to that obtained from the fermentation of $S$. cerevisiae pure cultures. Data showed significant production of $\mathrm{SA}$ in all the co-cultures, with a decrease of $\mathrm{pH}$, recording a value of 5.56, 5.32 for microaerobic and anaerobic co-cultures and 5.24 for sequential co-cultures. The SA produced from co-cultures in microaerobic and anaerobic conditions was significantly lower when compared with the anaerobic control A. succinogenes, while the glycerol amount produced rose in the sequential fermentations, wherein the fermentation performance of $S$. cerevisiae strain was important (table 2). Considering the organic acid production, an increase in SA levels was noticed in the sequential culture at $48 \mathrm{~h}$ when compared to the co-culture, while that from the pure fermentation of A. succinogenes in anaerobic culture was greater when compared to those obtained by the simultaneous and the sequential $48 \mathrm{~h}$ aerobic co-cultures. As for the sugars contents present in the fermentations media, the data displays a high consumption of the glucose and fructose; by $85 \%, 90 \%$ for both microaerobic and anaerobic simultaneous co-cultures and by $60 \%$ for sequential $48 \mathrm{~h}$ co-culture fermentations with respect to the control of $A$. succinogenes. On the other side, the microaerobic co-cultures lead to a decrease in $\mathrm{pH}$, with a succinic acid production, which was significantly detected, even if it remained considerably below the control level of $A$. succinogenes anaerobic fermentation. A development reflecting that the co-culture of A. succinogenes with $S$. cerevisiae generally showed the ability to produce SA, even in microaerobic conditions.

Sequential 48-hour cultures led to a $0.14 \mathrm{~g} \mathrm{~L}^{-1} \mathrm{~h}^{-1} \mathrm{SA}$ production rate in a lab-scale $(1.8 \mathrm{~L})$, reaching to about an $85 \%$ substrate conversion efficiency, recording an overall yield of 0.69 
mol-C of added chemical produced/ mol-C sugars consumed, with 54\% of carbon content belonging to succinic acid. The results emphasize the efficiency of the co-culture for the biological conversion of sugars to SA and might work in parallel to other succinic acid production processes such as the chemical process, or the anaerobic fermentation. Even though the system differs from earlier studies, the results are consistent with those obtained by [7, 29, 33] in terms of SA concentration, yield and productivity. To sum up, this provides a process for the batchwise fermentation of succinic acid, wherein a carbon dioxide from $S$. cerevisiae is maintained in a fermentation vessel then withdrawing the broth from the vessel and re-filling the vessel with a newly substrate, and preparing it for the reception of a subsequent batch of $A$. succinogenes to produce SA by fermenting the sugars.

\section{Effect of the fermentation temperature}

Fig. 4 (a- and b) present the evolution of the concentration of sugar during the fermentations in S. cerevisiae and A. succinogenes control cultures and in the co-cultures at the different optimal fermentation temperatures of $28^{\circ} \mathrm{C}$ and $37^{\circ} \mathrm{C}$, respectively. At both temperatures, the coculture fermentations evolved more gradually than in the pure strain culture fermentations expected for the $S$. cerevisiae at $28^{\circ} \mathrm{C}$. The biomass progression in terms of the OD, $\mathrm{pH}$, residual sugars concentrations and product concentrations in the pure culture and the co-cultures fermentations are given in table 3 at 28 and $37^{\circ} \mathrm{C}$. In the pure culture, S. cerevisiae start from 0.04 at t0 and achieved its highest optical density value in 16 hours (around 1.2), which remained almost constant till the end of fermentation (4 days), and the remaining sugar was below $0.02 \mathrm{~mol} \mathrm{~L}^{-1}$. Once the two microbial strains were co-inoculated (A. succinogenes and $S$. cerevisiae), with 0.04 starter OD, the cell concentration was less than that of $S$. cerevisiae, and reached a value of 0.38 and 0.36 at $28^{\circ} \mathrm{C}$ and $37^{\circ} \mathrm{C}$ respectively, when the fermentation was almost over (after $96 \mathrm{~h})$. Thus, at these fermentation conditions $\left(28^{\circ} \mathrm{C}\right)$, A. succinogenes 
showed an inhibitory activity in the production of SA even in anaerobic conditions $(0.07 \mathrm{~mol}$ $\mathrm{L}^{-1} \mathrm{SA}$ ) when compared to the amounts obtained at $37^{\circ} \mathrm{C}$. The compositional profiles of parameters collected in pure and co-culture fermentations at $28^{\circ} \mathrm{C}$ and $37^{\circ} \mathrm{C}$ are listed in Table 3. At $37^{\circ} \mathrm{C}$ and contrarily to $28^{\circ} \mathrm{C}$, the co-cultured A. succinogenes and S. cerevisiae showed a decrease in the amount of ethanol and remaining sugar, when compared to the control of $S$. cerevisiae alone. With respect to $S$. cerevisiae controls, the co-culture mode indicated a notable increase in the ethanol production at $28^{\circ} \mathrm{C}$, whereas a reduction in ethanol was noticed at $37^{\circ} \mathrm{C}$. Regarding the total production activity, the levels significantly increased from the coculture at both $28^{\circ} \mathrm{C}$ and $37{ }^{\circ} \mathrm{C}$, in comparison to their relevant $S$. cerevisiae controls at $37{ }^{\circ} \mathrm{C}$. This increase in ethanol at $28^{\circ} \mathrm{C}\left(0.08 \mathrm{~mol} \mathrm{~L}^{-1}\right)$ was significantly higher than at $37^{\circ} \mathrm{C}(0.05 \mathrm{~mol}$ $\left.\mathrm{L}^{-1}\right)$. There was a substantial increase of glycerol formed, when the co-cultures were run at $28^{\circ} \mathrm{C}$ $\left(0.06 \mathrm{~mol} \mathrm{~L}^{-1}\right)$ with regard to the control. The coupling of $A$. succinogenes $-S$. cerevisiae in microaerobic co-culture at $37{ }^{\circ} \mathrm{C}$, has a positive impact on the sugar consumption, resulting in SA formation with levels of $0.22 \mathrm{~mol} \mathrm{~L}^{-1}$, with respect to SA levels obtained from $A$. succinogenes pure cultures $\left(0.3 \mathrm{~mol} \mathrm{~L}^{-1}\right)$. This suggests that $\mathrm{SA}$ production in microaerobic coculture is primarily impressed by an $S$. cerevisiae coupling and by the different temperature conditions.

Considering the sequential 48 hour- fermentations (Fig 5-a), no production of SA was observed before the bacterial inoculation and the temperature shift at $37^{\circ} \mathrm{C}$; the final SA value was 0.27 mol L $\mathrm{L}^{-1}$ corresponding to a $0.33 \mathrm{~g} \mathrm{~L}^{-1} \mathrm{~h}^{-1}$ productivity. Moreover, there was a general decrease in the profile of volatile compounds production with an increase of succinic acid; when the fermentations were performed at $37^{\circ} \mathrm{C}$, with a smaller variation for $S$. cerevisiae and $A$. succinogenes monocultures. Meanwhile, as compared to the respective controls along with the highest SA production, there was a significant glucose consumption with a substantial decrease of glycerol which might be attributed to the use of the yeast/bacteria as carbon source described 
in many papers $[15,28,34]$. The percentage of Dissolved Oxygen (DO) in the medium Fig 6b was found to have a considerable influence upon the OD value under conditions of rapid fermentation at $28^{\circ} \mathrm{C}$. At T0, the DO content in the substrate was $100 \%$, the ethanol concentration reached about $0.05 \mathrm{~mol} \mathrm{~L}^{-1}$ in the substrates containing $43 \% \mathrm{DO}$ after $48 \mathrm{~h}$, and the glycerol concentration reached about $0.04 \mathrm{~mol} \mathrm{~L}^{-1}$ after $48 \mathrm{~h}$, then decrease to about 0.005 mol L ${ }^{-1}$ after $120 \mathrm{~h}$ in the media containing $43 \%$ and $24 \%$ DO in the fermentation in which the DO was maintained at about $24 \%$, recording a maximum value of $0.27 \mathrm{~mol} \mathrm{L-1}$ of SA and a pH value of 4.6 after $120 \mathrm{~h}$.

\section{Discussion}

Microbial co-cultures can be used to produce a variety of products ranging from small molecules, such as hydrogen or short chain fatty acids, to more products, such as methane, acetate, butanol, pyruvate, butyrate and alcohols (table 4). The co-culture strategy for SA production has been known for a long time. On the contrary, the concepts of the co-cultures strategies are new. To our knowledge, the co-culture of A. succinogenes and S. cerevisiae was not investigated beforehand. Here, in the present work, the co-culture was proposed as an alternative inoculation strategy to the traditional fermentation culture to produce succinic acid. It was previously checked that co-cultures of yeasts/bacteria pairs carried out in $250 \mathrm{~mL}$ bottles gave similar results as those obtained during pure cultures. Tremendous numbers of data have been published regarding the function relayed on bacteria or yeasts to produce chemicals alone, yet, reports on "if" or "how" they interact mutually together, start to be in the scope of interest recently. In both described co-cultures, the A. succinogenes strain was able to grow on in the presence of S. cerevisiae, using glucose and fructose as substrates. As observed, the co-culture had only a little effect on the optical cell density compared to the pure cultures; however, $S$. cerevisiae led to a higher cell density than A. succinogenes over the whole culture (Fig 1). This 
might be due to the fact that $S$. cerevisiae displayed a higher inoculum size which can favourably impact the optical density [35]. The simultaneous co-occurrence of both strains had a smaller impact than the pure cultures in the fermentation systems. Thus, next to providing the co-substrate for the partner strain, the properties of S. cerevisiae strain make co-cultivation possible [36]

The study was realised in a synthetic medium to obtain a reproducible medium with a controlled and non-limiting composition. In microaerobic conditions, the advantage of the co-culture strategy over the monoculture could be due to the presence of yeast from the beginning in a medium lacking $\mathrm{MgCO}_{3}$ unlike the fermented medium used for monocultures (Fig. 2 and Table 2). Some of the yeast inhibitory metabolites produced by the $S$. cerevisiae strain, such as ethanol, were measured at the end of the co-culture (Fig 2, 3 and Table 2). These inhibitory compounds are known to limit bacterial growth and could reduce the ability of bacteria to synthesize SA at different levels depending on their concentrations and the medium composition and $\mathrm{pH}$ during co-culture [16, 37-39] Even though these metabolites gradually occurred during the sequential culture, which lasted for $144 \mathrm{~h}$ of the co-culture, the bacteria had time to grow and specially to produce SA (Fig. 4 and Table 3). The SA amounts were higher than those obtained in the simultaneous co-culture, which might be referred to the accumulation of $\mathrm{CO}_{2}$ in the reactor which stimulates the production of succinic acid when applied directly to the bacteria, in addition to the reactor form and volume used in a sequential culture which is different with that used in the simultaneous co-culture.

It is generally recognised that glucose is consumed rapidly by both of $S$. cerevisiae and $A$. succinogenes $[8,40]$. Accordingly, in sequential $48 \mathrm{~h}$ fermentations with $S$. cerevisiae as a starter, it was observed that the residual fructose concentration was substantially greater, with a higher discrepancy between glucose and fructose concentrations (Fig 4). From the collected data, we deduced that a lower fructose amount was used during the sequential culture if 
compared to the fructose consumption in pure S. cerevisiae and simultaneous co-cultures. As observed, the consumption of both sugars was less than those obtained during the sequential culture.

In our study, considering the simultaneous microaerobic co-culture, besides the ethanol and glycerol productions, a stimulatory effect of $S$. cerevisiae on $A$. succinogenes to produce SA was observed, as drawn from the comparison to the A. succinogenes monoculture. Based on a physiological analysis, it was noticed that co-cultivation resulted in significant SA production by A. succinogenes during the whole culture.

Interestingly, no major changes were found regarding biomass amounts when comparing monoand co-culture conditions, suggesting that no changes took place on the genetic level. The product shift appears to be caused by changes in the thermodynamics of the system resulting in more $\mathrm{CO}_{2}$ production as described by [41], inducing favorable conditions for succinate production as a result of an A. succinogenes metabolism. An example of a metabolic shift driven by a metabolic interaction is the co-cultivation of Escherichia coli grown on glycerol together with the formate-oxidizing methanogen Methanobacterium formicicum. Natively, E. coli produces mainly ethanol and formate as end-product of glycerol fermentation, with succinate and acetate as byproducts. In co-culture with $M$. formicicum, the spectrum shifts to succinate production instead [42]. A similar interaction also seems to have taken place in the case of the sequential $48 \mathrm{~h}$ co-culture, facilitating substrate and $\mathrm{CO}_{2}$ conversion by the $A$. succinogenes.

For the sequential co-culture fermentation from substrate to succinic acid, the main challenges were the requirements of the involved microorganisms in terms of reactor set-up, medium composition and product synthesis. Optimizing product yield and productivity for a certain process usually addresses the needs of the organism involved. Since sequential co-culture fermentation uses at least two different organisms, the key aspect for sequential co-culture 
fermentation is either a medium compromise for both organisms or the compatibility of the first (optimized) medium for the second organism in terms of product synthesis. Furthermore, the second organism has to be able to use the product of the first process as a carbon source. The combination of both aspects must be fulfilled to achieve an optimal value added chain from sugars to succinic acid. Exchange of metabolites synthesized in different microbes can take also place. An example of this is the co-culture of Clostridium ljungdahlii and Clostridium acetobutylicum (table 4). While the products 2,3-butanediol and isopropanol were not formed from glucose by monocultures, the co-cultivation of $C$. ljungdahlii and $C$. acetobutylicum have resulted in the increased formation of 2,3-butanediol and isopropanol [43].

However, co-culture technology can display some drawbacks, which should be taken into consideration, such as the need to build various microbial pools, the requirement to survey and control microbial population and the prospects to engineer a transport model of metabolites between two upstream methods in one system, which, on high- scale, present a roadblock.

\section{Conclusions}

Overall, the co-culture approach appears interesting from both application and fundamental points of view. We could successfully show that the production of succinic acid from sequential co-culture is possible by a temperature shift. The advantage of this kind of biotechnological process is the extension of the product portfolio of anaerobic fermentation. The work at hand demonstrates that $A$. succinogenes is able to use glycerol as a substrate for succinic acid formation. Moreover, it shows that it is possible to link aerobic fermentation to succinic acid production using sequential co-cultures of $S$. cerevisiae and A. succinogenes. Currently, production rates obtained in our study were about $0.3 \mathrm{~g} \mathrm{~L}^{-1} \mathrm{~h}^{-1}$ from a sequential 48 co-culture, which is promising in view of the production of SA at a large scale, but they still have to be improved to become commercially interesting. Yet, based on the reported co-culture, as 
compared with other strategies traditionally used in SA production research, co-culture can be done and give similar results from microbial pure cultures (co-culture strategy gives the same results from a pure culture without the use of a mineral carbon source such as $\mathrm{MgCO}_{3}$ and the nitrogen sparging). Additionally, this research shows how important microbial interactions and thermodynamic interactions in a microbial-community are, besides the syntrophic systems described in the literature. Evaluation studies of efficiency, environmental impact and cost assessment will also be very interesting. The field still has several major obstacles to go through before stable scale-up studies can be a reality.

\section{Acknowledgments}

The authors thank Ivane LELIEVRE (Unilasalle-EME) for her technical help and Marie-Anne Hairan (UniLasalle-EME) for her helpful comments for improving the English. The authors would like to thank Bebnine municipality, North-Lebanon for financial support through the Program Education of Lebanese student.

\section{Ethical Approval}

This article followed the ethical standard of the institute.

\section{Consent to Participate}

All authors consented to participation in this research.

\section{Consent to publish}

All authors consented to publish this research in this journal.

\section{Authors contribution}


Alaa SALMA made substantial contributions to the design of the work, performed the experiments, the analysis and wrote the manuscript. Hayet DJELAL, Abdeltif AMRANE, Florence FOURCADE and Rawa ABDALLAH supervised the work, revised the manuscript critically for important intellectual content and approved the version to be published.

\section{Funding}

This research did not receive any specific grant from funding agencies in the public, commercial, or not-for-profit sectors.

\section{Competing interests}

The authors declare that they have no known competing financial interests or personal relationships that could have appeared to influence the work reported in this article.

\section{Availability of data and materials}

The authors declare that the data and materials are transparent. 


\section{References}

1. Taylor, R. (2015). From the Sugar Platform to biofuels and biochemicals, 183.

2. Fu, J., Vasiliadou, E. S., Goulas, K. A., Saha, B., \& Vlachos, D. G. (2017). Selective hydrodeoxygenation of tartaric acid to succinic acid. Catalysis Science \& Technology, 7(21), 4944-4954. https://doi.org/10.1039/C7CY01374D

3. Amulya, K., \& Mohan, S. V. (2019). Fixation of CO2, electron donor and redox microenvironment regulate succinic acid production in Citrobacter amalonaticus. Science of The Total Environment, 695, 133838.

https://doi.org/10.1016/j.scitotenv.2019.133838

4. Tan, J. P., Luthfi, A. A. I., Manaf, S. F. A., Wu, T. Y., \& Jahim, J. Md. (2018). Incorporation of $\mathrm{CO} 2$ during the production of succinic acid from sustainable oil palm frond juice. Journal of CO2 Utilization, 26, 595-601. https://doi.org/10.1016/j.jcou.2018.06.006

5. Bradfield, M. F. A., Mohagheghi, A., Salvachúa, D., Smith, H., Black, B. A., Dowe, N., ... Nicol, W. (2015). Continuous succinic acid production by Actinobacillus succinogenes on xylose-enriched hydrolysate. Biotechnology for Biofuels, 8. https://doi.org/10.1186/s13068-015-0363-3

6. Pinazo, J., Dómine, M., Parvulescu, V., \& Filip, P. (2015). Sustainability metrics for succinic acid production: A comparison between biomass-based and petrochemical routes. Catalysis Today, 239, 17-24. https://doi.org/10.1016/j.cattod.2014.05.035

7. Almqvist, H., Pateraki, C., Alexandri, M., Koutinas, A., \& Lidén, G. (2016). Succinic acid production by Actinobacillus succinogenes from batch fermentation of mixed sugars. Journal of Industrial Microbiology \& Biotechnology, 43(8), 1117-1130. https://doi.org/10.1007/s10295-016-1787-x 
8. Ferone, M., Raganati, F., Ercole, A., Olivieri, G., Salatino, P., \& Marzocchella, A. (2018). Continuous succinic acid fermentation by Actinobacillus succinogenes in a packed-bed biofilm reactor. Biotechnology for Biofuels, 11 . https://doi.org/10.1186/s13068-018-1143-7

9. Zou, W., Zhu, L.-W., Li, H.-M., \& Tang, Y.-J. (2011). Significance of CO2 donor on the production of succinic acid by Actinobacillus succinogenes ATCC 55618. Microbial cell factories, 10, 87. https://doi.org/10.1186/1475-2859-10-87

10. Herselman, J. (2017). Rate and yield dependency of Actinobacillus succinogenes on dissolved CO2 concentration. University of Pretoria. Retrieved from https://repository.up.ac.za/handle/2263/61295

11. Atasoy, M., Eyice, O., Schnürer, A., \& Cetecioglu, Z. (2019). Volatile fatty acids production via mixed culture fermentation: Revealing the link between $\mathrm{pH}$, inoculum type and bacterial composition. Bioresource Technology, 292, 121889. https://doi.org/10.1016/j.biortech.2019.121889

12. Ferone, M., Raganati, F., Olivieri, G., \& Marzocchella, A. (2019). Bioreactors for succinic acid production processes. Critical Reviews in Biotechnology, 39(4), 571-586. https://doi.org/10.1080/07388551.2019.1592105

13. Pinkian, N., Phuengjayaem, S., Tanasupawat, S., \& Teeradakorn, S. (2018). Optimization of succinic acid production by succinic acid bacteria isolated in Thailand, 10.

14. Jiang, M., Ma, J., Wu, M., Liu, R., Liang, L., Xin, F., ... Dong, W. (2017). Progress of succinic acid production from renewable resources: Metabolic and fermentative strategies. Bioresource Technology, 245, 1710-1717. https://doi.org/10.1016/j.biortech.2017.05.209 
15. Sadhukhan, S., Villa, R., \& Sarkar, U. (2016). Microbial production of succinic acid using crude and purified glycerol from a Crotalaria juncea based biorefinery. Biotechnology Reports, 10, 84-93. https://doi.org/10.1016/j.btre.2016.03.008

16. Ahn, J. H., Jang, Y.-S., \& Lee, S. Y. (2016). Production of succinic acid by metabolically engineered microorganisms. Current Opinion in Biotechnology, 42, 5466. https://doi.org/10.1016/j.copbio.2016.02.034

17. Sabra, W., \& Zeng, A. (2014). Mixed microbial cultures for industrial biotechnology: Success, chance, and challenges.

18. Liu, Y.-P., Zheng, P., Sun, Z.-H., Ni, Y., Dong, J.-J., \& Wei, P. (2008). Strategies of pH control and glucose-fed batch fermentation for production of succinic acid by Actinobacillus succinogenes CGMCC1593. Journal of Chemical Technology \& Biotechnology, 83(5), 722-729. https://doi.org/10.1002/jctb.1862

19. Kleerebezem, R., \& van Loosdrecht, M. C. M. (2007). Mixed culture biotechnology for bioenergy production. Current Opinion in Biotechnology, 18(3), 207-212. https://doi.org/10.1016/j.copbio.2007.05.001

20. Bader, J., Brigham, C. J., Stahl, U., \& Popović, M. K. (2019). 3 - Fermented Beverages Produced by Mixed Cultures, Pure Cultures, and Defined Cocultures. In A. M. Grumezescu \& A. M. Holban (Eds.), Fermented Beverages (pp. 67-101). Woodhead Publishing. https://doi.org/10.1016/B978-0-12-815271-3.00003-8

21. Shen, N., Dai, K., Xia, X.-Y., Zeng, R., \& Zhang, F. (2018). Conversion of syngas (CO and $\mathrm{H} 2$ ) to biochemicals by mixed culture fermentation in mesophilic and thermophilic hollow-fiber membrane biofilm reactors. Journal of Cleaner Production, 202. https://doi.org/10.1016/j.jclepro.2018.08.162

22. Djelal, H., Chniti, S., Jemni, M., Weill, A., Sayed, W., \& Amrane, A. (2017). Identification of strain isolated from dates (Phœnix dactylifera L.) for enhancing very 
high gravity ethanol production. Environmental Science and Pollution Research International, 24(11), 9886-9894. https://doi.org/10.1007/s11356-016-8018-x

23. Jones, J. A., \& Wang, X. (2018). Use of bacterial co-cultures for the efficient production of chemicals. Current Opinion in Biotechnology, 53, 33-38. https://doi.org/10.1016/j.copbio.2017.11.012

24. Marmann, A., Aly, A. H., Lin, W., Wang, B., \& Proksch, P. (2014). Co-Cultivation-A Powerful Emerging Tool for Enhancing the Chemical Diversity of Microorganisms. Marine Drugs, 12(2), 1043-1065. https://doi.org/10.3390/md12021043

25. Liu, H., Hu, H., Jin, Y., Yue, X., Deng, L., Wang, F., \& Tan, T. (2017). Co-fermentation of a mixture of glucose and xylose to fumaric acid by Rhizopus arrhizus RH 7-13-9\#. Bioresource Technology, 233, 30-33. https://doi.org/10.1016/j.biortech.2017.02.035

26. Lu, H., Villada, J. C., \& Lee, P. K. H. (2019). Modular Metabolic Engineering for Biobased Chemical Production. Trends in Biotechnology, 37(2), 152-166. https://doi.org/10.1016/j.tibtech.2018.07.003

27. Gonzales, T. A., Carvalho Silvello, M. A. de, Duarte, E. R., Santos, L. O., Alegre, R. M., \& Goldbeck, R. (2020). Optimization of anaerobic fermentation of Actinobacillus succinogenes for increase the succinic acid production. Biocatalysis and Agricultural Biotechnology, 27, 101718. https://doi.org/10.1016/j.bcab.2020.101718

28. Djelal, H., Amrane, A., Lahrer, F., \& Martin, G. (2005). Effect of medium osmolarity on the bioproduction of glycerol and ethanol by Hansenula anomala growing on glucose and ammonium. Applied Microbiology and Biotechnology, 69(3), 341-349. https://doi.org/10.1007/s00253-005-1987-1

29. Carvalho, M., Roca, C., \& Reis, M. A. M. (2016). Improving succinic acid production by Actinobacillus succinogenes from raw industrial carob pods. Bioresource Technology, 218, 491-497. https://doi.org/10.1016/j.biortech.2016.06.140 
30. Walker, G. M., \& Stewart, G. G. (2016). Saccharomyces cerevisiae in the Production of Fermented Beverages. Beverages, 2(4), 30. https://doi.org/10.3390/beverages2040030

31. Tronchoni, J., Curiel, J. A., Morales, P., Torres-Perez, R., \& Gonzalez, R. (2017). Early transcriptional response to biotic stress in mixed starter fermentations involving Saccharomyces cerevisiae and Torulaspora delbrueckii. International Journal of Food Microbiology, 241, 60-68. https://doi.org/10.1016/j.ijfoodmicro.2016.10.017

32. Cao, W., Wang, Y., Luo, J., Yin, J., Xing, J., \& Wan, Y. (2018). Effectively converting carbon dioxide into succinic acid under mild pressure with Actinobacillus succinogenes by an integrated fermentation and membrane separation process. Bioresource Technology, 266, 26-33. https://doi.org/10.1016/j.biortech.2018.06.016

33. Corona-González, R. I., Bories, A., González-Álvarez, V., \& Pelayo-Ortiz, C. (2008). Kinetic study of succinic acid production by Actinobacillus succinogenes ZT-130. Process Biochemistry, 43(10), 1047-1053. https://doi.org/10.1016/j.procbio.2008.05.011

34. Schindler Bryan David. (2011). Understanding and improving respiratory succinate production from glycerol by Actinobacillus succinogenes. Michigan State University.

35. Pereira, A. P., Mendes-Ferreira, A., Oliveira, J. M., Estevinho, L. M., \& Mendes-Faia, A. (2013). High-cell-density fermentation of Saccharomyces cerevisiae for the optimisation of mead production. Food Microbiology, 33(1), 114-123. https://doi.org/10.1016/j.fm.2012.09.006

36. Reis, V. R., Bassi, A. P. G., Cerri, B. C., Almeida, A. R., Carvalho, I. G. B., Bastos, R. G., \& Ceccato-Antonini, S. R. (2018). Effects of feedstock and co-culture of Lactobacillus fermentum and wild Saccharomyces cerevisiae strain during fuel ethanol fermentation by the industrial yeast strain PE-2. AMB Express, 8(1), 23. https://doi.org/10.1186/s13568-018-0556-9 
37. McKinlay, J. B., Zeikus, J. G., \& Vieille, C. (2005). Insights into Actinobacillus succinogenes fermentative metabolism in a chemically defined growth medium. Applied and Environmental Microbiology, 71(11), 6651-6656. https://doi.org/10.1128/AEM.71.11.6651-6656.2005

38. Nag, A., John, P. C. S., Crowley, M. F., \& Bomble, Y. J. (2018). Prediction of reaction knockouts to maximize succinate production by Actinobacillus succinogenes. PLOS ONE, 13(1), e0189144. https://doi.org/10.1371/journal.pone.0189144

39. Cheng, K.-K., Wang, G.-Y., Zeng, J., \& Zhang, J.-A. (2013). Improved Succinate Production by Metabolic Engineering. BioMed Research International. Research article. https://doi.org/10.1155/2013/538790

40. Bušić, A., Marđetko, N., Kundas, S., Morzak, G., Belskaya, H., Ivančić Šantek, M., ... Šantek, B. (2018). Bioethanol Production from Renewable Raw Materials and Its Separation and Purification: A Review. Food Technology and Biotechnology, 56(3), 289-311. https://doi.org/10.17113/ftb.56.03.18.5546

41. Kimberly Chen, Klous C. Cui, \& Jinny Choi. (2013). The effect of temperature on the carbon dioxide production of Saccharomyces cerevisiae as measured by the change in volume of carbon dioxide produced. Retrieved from https://ojs.library.ubc.ca/index.php/expedition/article/view/184143

42. Kim, N. Y., Kim, S. N., \& Kim, O. B. (2018). Long-term adaptation of Escherichia coli to methanogenic co-culture enhanced succinate production from crude glycerol. Journal of Industrial Microbiology \& Biotechnology, 45(1), 71-76.

https://doi.org/10.1007/s10295-017-1994-0

43. Charubin, K., Modla, S., Caplan, J. L., \& Papoutsakis, E. T. (2020). Interspecies Microbial Fusion and Large-Scale Exchange of Cytoplasmic Proteins and RNA in a Syntrophic Clostridium Coculture. mBio, 11(5). https://doi.org/10.1128/mBio.02030-20 
44. Diender, M., Uhl, P. S., Bitter, J. H., Stams, A. J. M., \& Sousa, D. Z. (2018). High Rate Biomethanation of Carbon Monoxide-Rich Gases via a Thermophilic Synthetic Coculture. ACS Sustainable Chemistry \& Engineering, 6(2), 2169-2176. https://doi.org/10.1021/acssuschemeng.7b03601

45. Richter, H., Molitor, B., Diender, M., Sousa, D. Z., \& Angenent, L. T. (2016). A Narrow pH Range Supports Butanol, Hexanol, and Octanol Production from Syngas in a Continuous Co-culture of Clostridium ljungdahlii and Clostridium kluyveri with In-Line Product Extraction. Frontiers in Microbiology, 7. https://doi.org/10.3389/fmicb.2016.01773

46. Diender, M., Parera Olm, I., Gelderloos, M., Koehorst, J. J., Schaap, P. J., Stams, A. J. M., \& Sousa, D. Z. (2019). Metabolic shift induced by synthetic co-cultivation promotes high yield of chain elongated acids from syngas. Scientific Reports, 9(1), 18081. https://doi.org/10.1038/s41598-019-54445-y

47. Moscoviz, R., de Fouchécour, F., Santa-Catalina, G., Bernet, N., \& Trably, E. (2017). Cooperative growth of Geobacter sulfurreducens and Clostridium pasteurianum with subsequent metabolic shift in glycerol fermentation. Scientific Reports, 7, 44334. https://doi.org/10.1038/srep44334

48. Salimi, F., \& Mahadevan, R. (2013). Characterizing metabolic interactions in a clostridial co-culture for consolidated bioprocessing. BMC biotechnology, 13, 95. https://doi.org/10.1186/1472-6750-13-95

49. Zhou, K., Qiao, K., Edgar, S., \& Stephanopoulos, G. (2015). Distributing a metabolic pathway among a microbial consortium enhances production of natural products. Nature Biotechnology, 33(4), 377-383. https://doi.org/10.1038/nbt.3095 
Figure 1 Optical density evolution during fermentations with different modes of inoculation in microaerobic (a) and anaerobic conditions (b) in the presence of $0.2 \mathrm{~mol} \mathrm{~L}^{-1} \mathrm{MgCO}_{3}$ except for the sequential culture. Pure culture fermentations of A. succinogenes (-ه-) and S. cerevisiae (口-). Co-cultures fermentations with a \% ratio of $(0.5 ; 0.5)$ of A. succinogenes and S. cerevisiae respectively. (- -$)$, and co-culture of $S$. cerevisiae with $A$. succinogenes addition after $48 \mathrm{~h}(---$ ). The arrow $(\mapsto)$ represent the inoculation of $A$. succinogenes in the sequential culture at $37^{\circ} \mathrm{C}$.

Figure 2 Fermentation kinetics (as sugars consumption and products formation) showing cocultures fermentation ratio in microaerobic conditions in the absence (a) or in the presence (b) of $0.2 \mathrm{~mol} \mathrm{~L}^{-1}$ of $\mathrm{MgCO}_{3}$ during fermentation at $37^{\circ} \mathrm{C}$ for a $\%$ volume ratio of $(0.5 ; 0.5)$, of $A$. succinogenes and S. cerevisiae, respectively.

Figure 3 Product time-courses during co-cultures in microaerobic and anaerobic conditions without $\mathrm{MgCO}_{3}$ during fermentation at $37^{\circ} \mathrm{C}$; a- for a $\%$ volume ratio of $(0.25 ; 0.75)$, and $\mathrm{b}$ - for a \% ratio of $(0.75 ; 0.25)$ of $S$. cerevisiae and $A$. succinogenes respectively. The filled character represents the products obtained from fermentation in microaerobic conditions (- -$)$ ethanol; (-) glycerol (- $\mathbf{\Delta}$-) SA and the empty character represent the products obtained from anaerobic

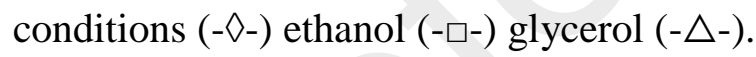

Figure 4 Fermentation parameters in term of sugars consumption during pure cultures (a) and co- cultures (b) at two different temperatures, $28^{\circ} \mathrm{C}$ and $37^{\circ} \mathrm{C}$ with a biomass $\%$ volume ratio of $(0.5 ; 0.5)$ for A. Succinogenes -S. cerevisiae respectively. (--) for A. succinogenes, (- -$)$ for S. cerevisiae, and (- $\mathbf{\Delta}-)$ for co- cultures.

Figure 5 Sequential $48 \mathrm{~h}$ cultures sugars consumption and products formations (a) without $\mathrm{MgCO}_{3}$ with $\mathrm{pH}$ and dissolved oxygen variation (b). The arrow $(\mapsto)$ represent the inoculation of $A$. succinogenes with the temperature shift from $28^{\circ} \mathrm{C}$ to $37^{\circ} \mathrm{C}$. 
(a)

Fig 1
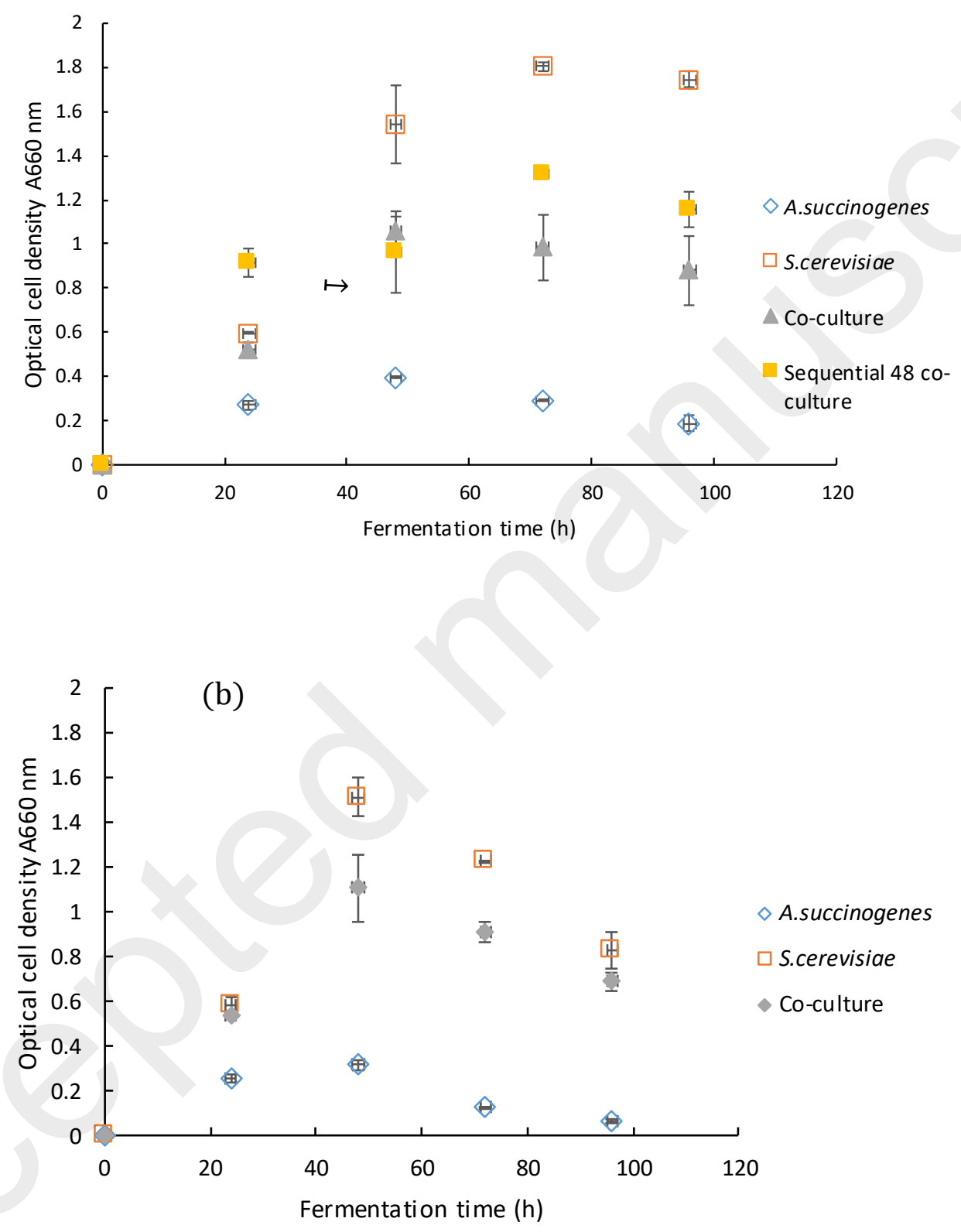
Fig 2

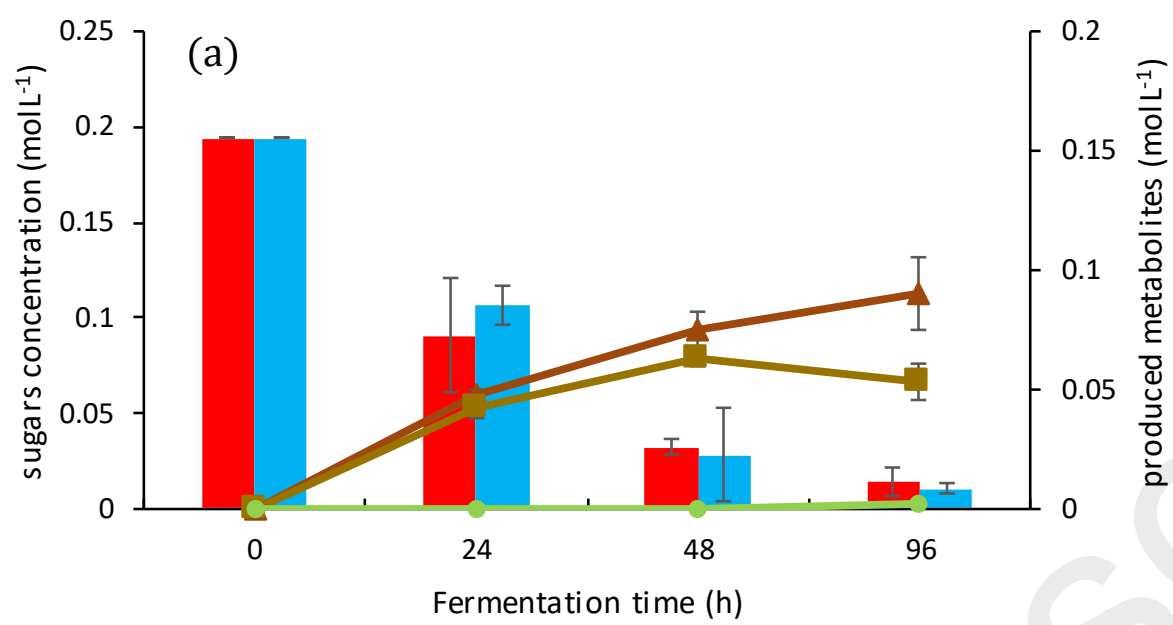

Glucose Fructose $\longrightarrow$ Ethanol $\longrightarrow$ Glycerol $\longrightarrow$ SA

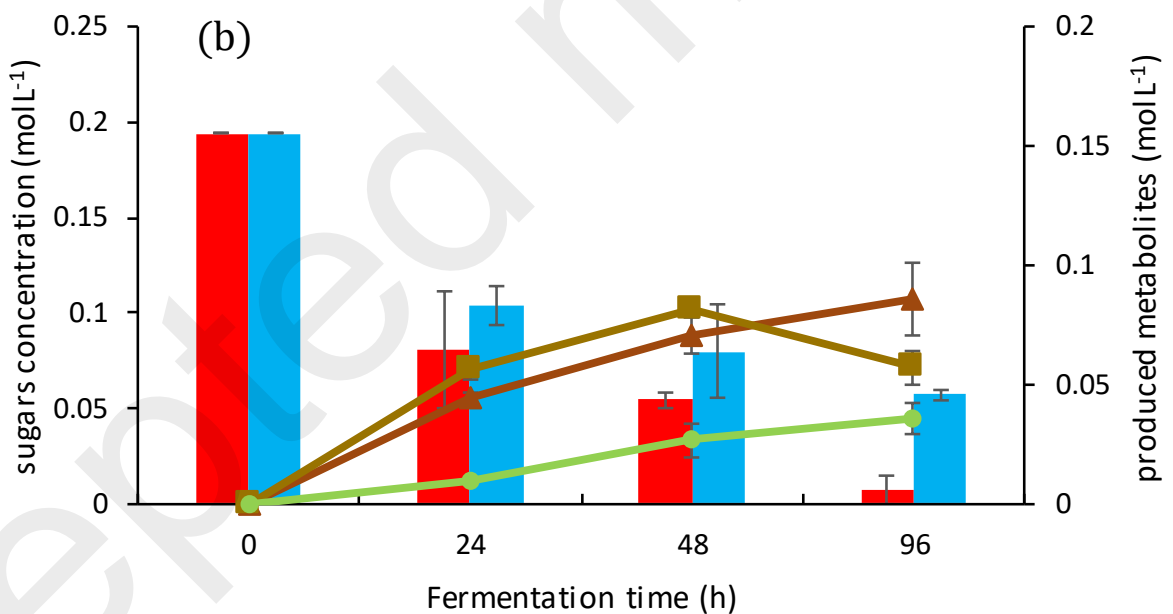

Glucose $\quad$ Fructose $\longrightarrow$ Ethanol $\quad$ Glycerol $\longrightarrow$ SA 
Fig 3

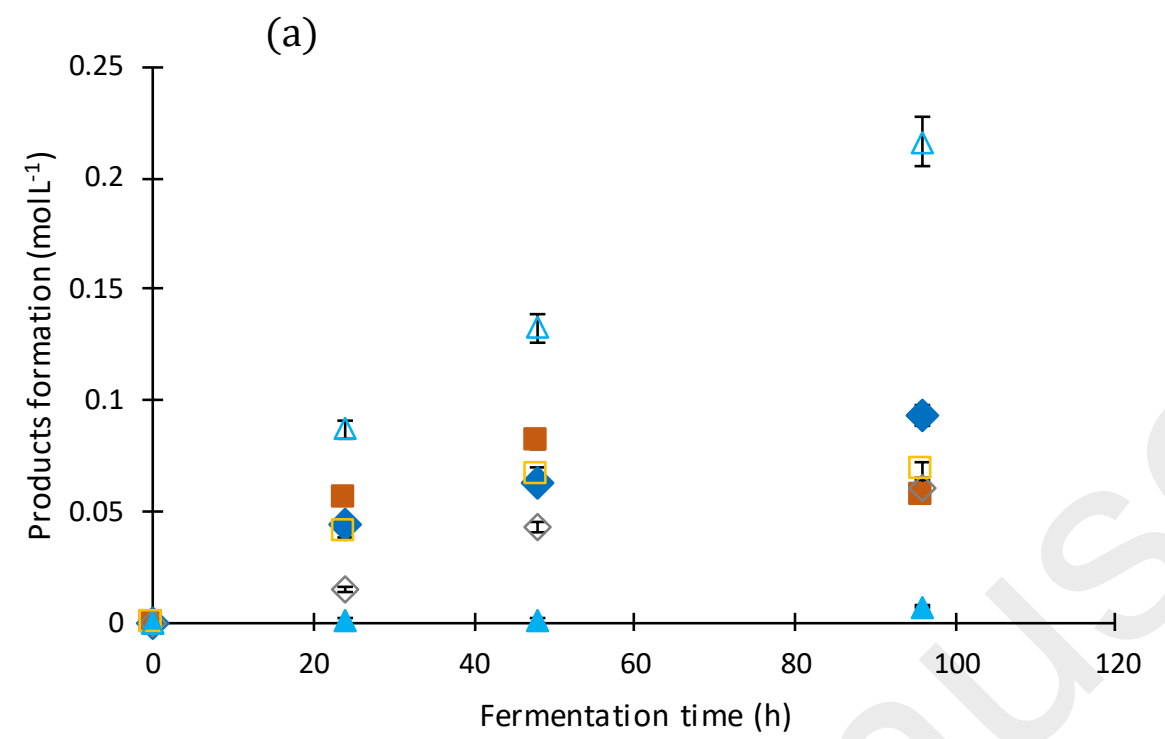

$\checkmark$ Ethanol Glycerol $\triangle \mathrm{SA} \diamond$ Ethanol $\square$ Glycerol $\triangle \mathrm{SA}$

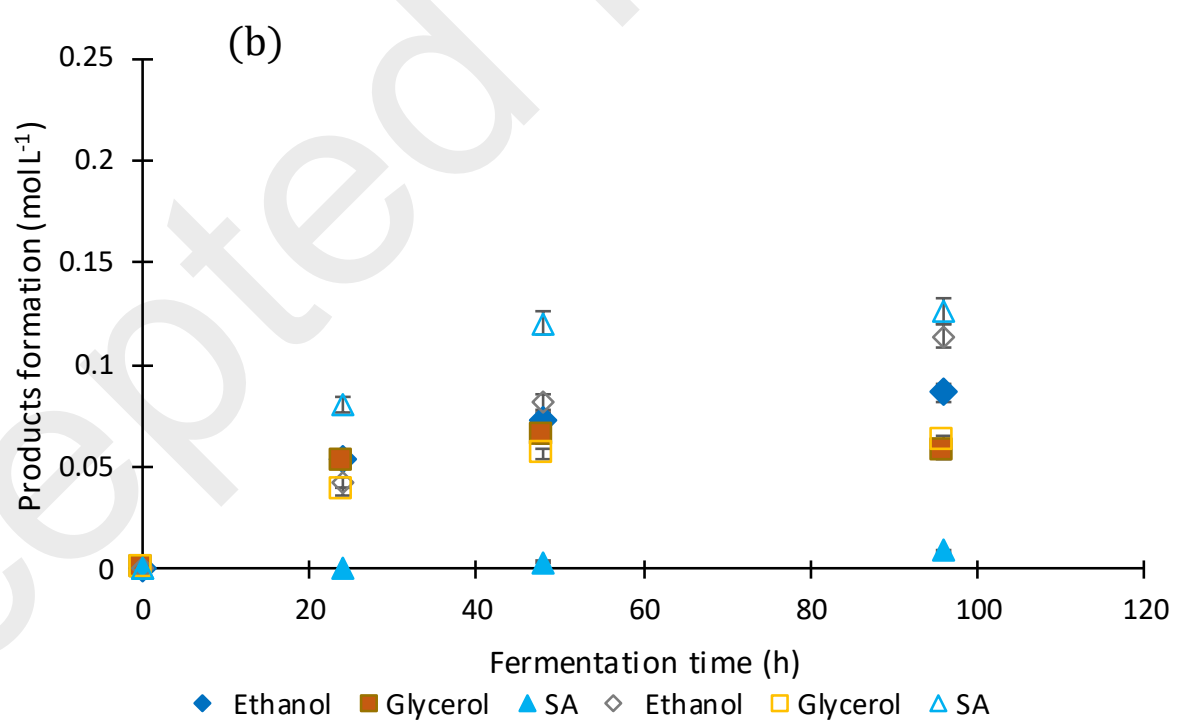


Fig 4

At $28^{\circ} \mathrm{C}$

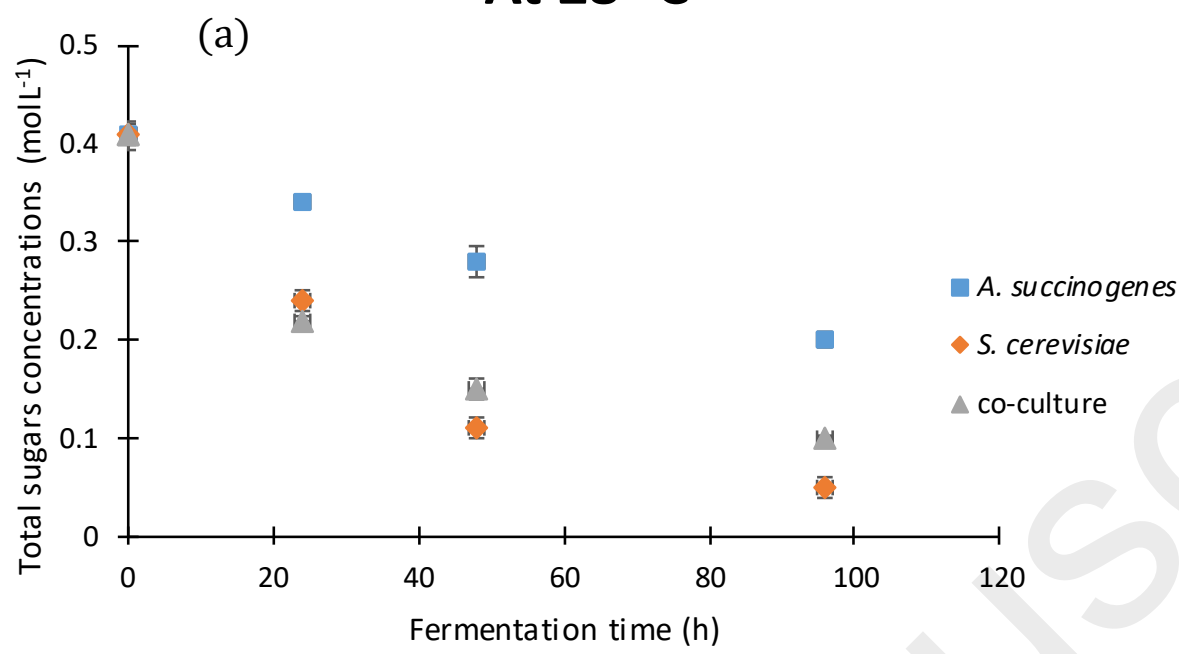

At $37^{\circ} \mathrm{C}$

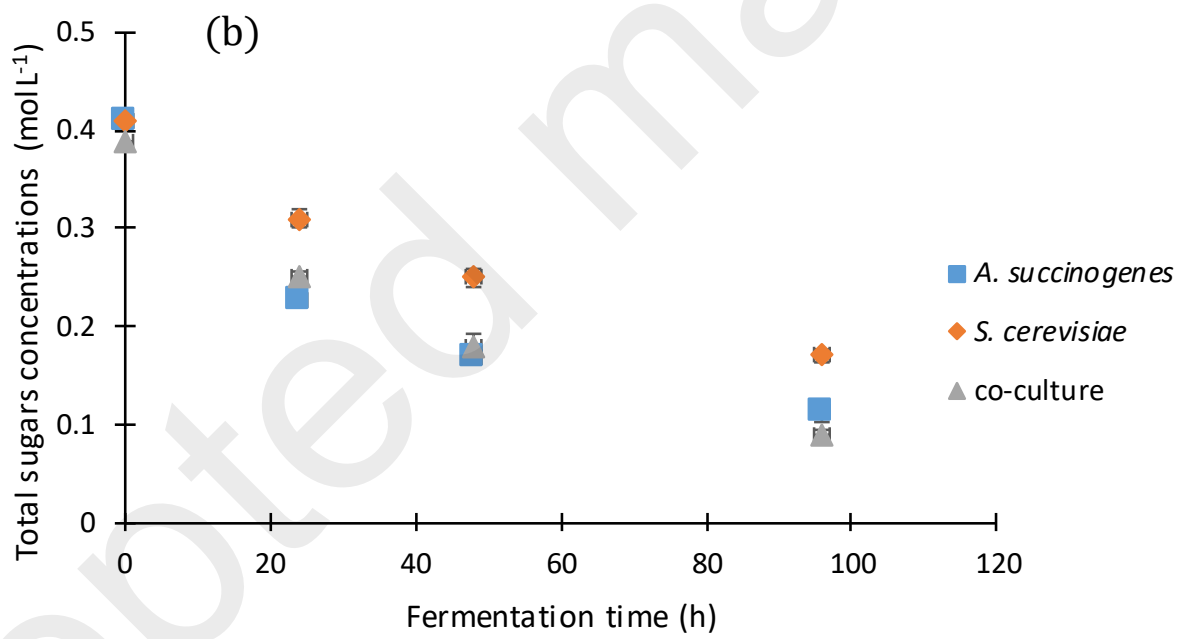


Fig 5
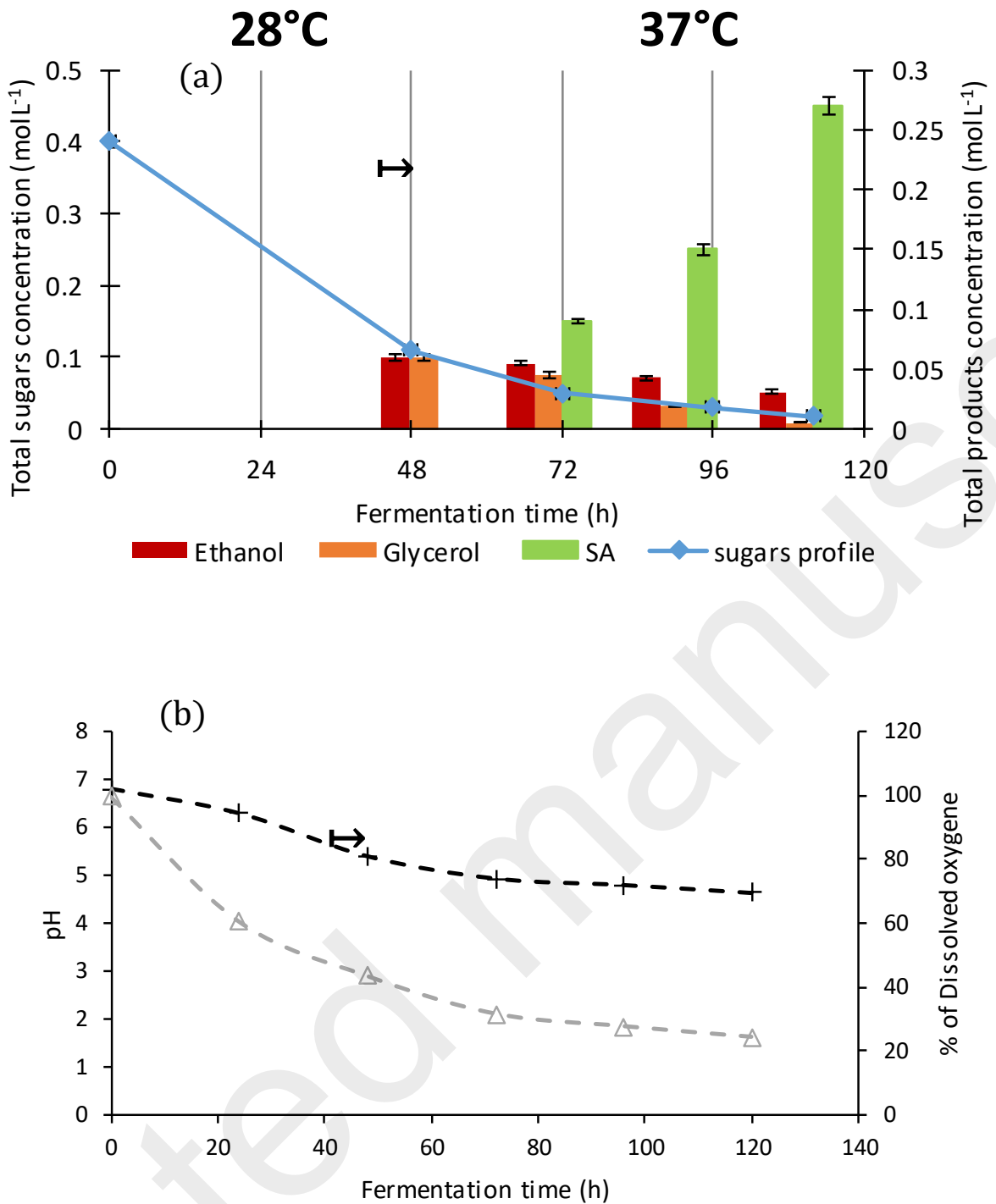

$-+-\mathrm{pH}-\triangleq-\mathrm{D} . \mathrm{O}$ 
Table 1 Influence of the mode of inoculation on the fermentation profile of A. succinogenes and $S$. cerevisiae pure culture at the end of fermentation time (48h). Data are duplicates from two independent experiments represented as a mean \pm standard deviation.

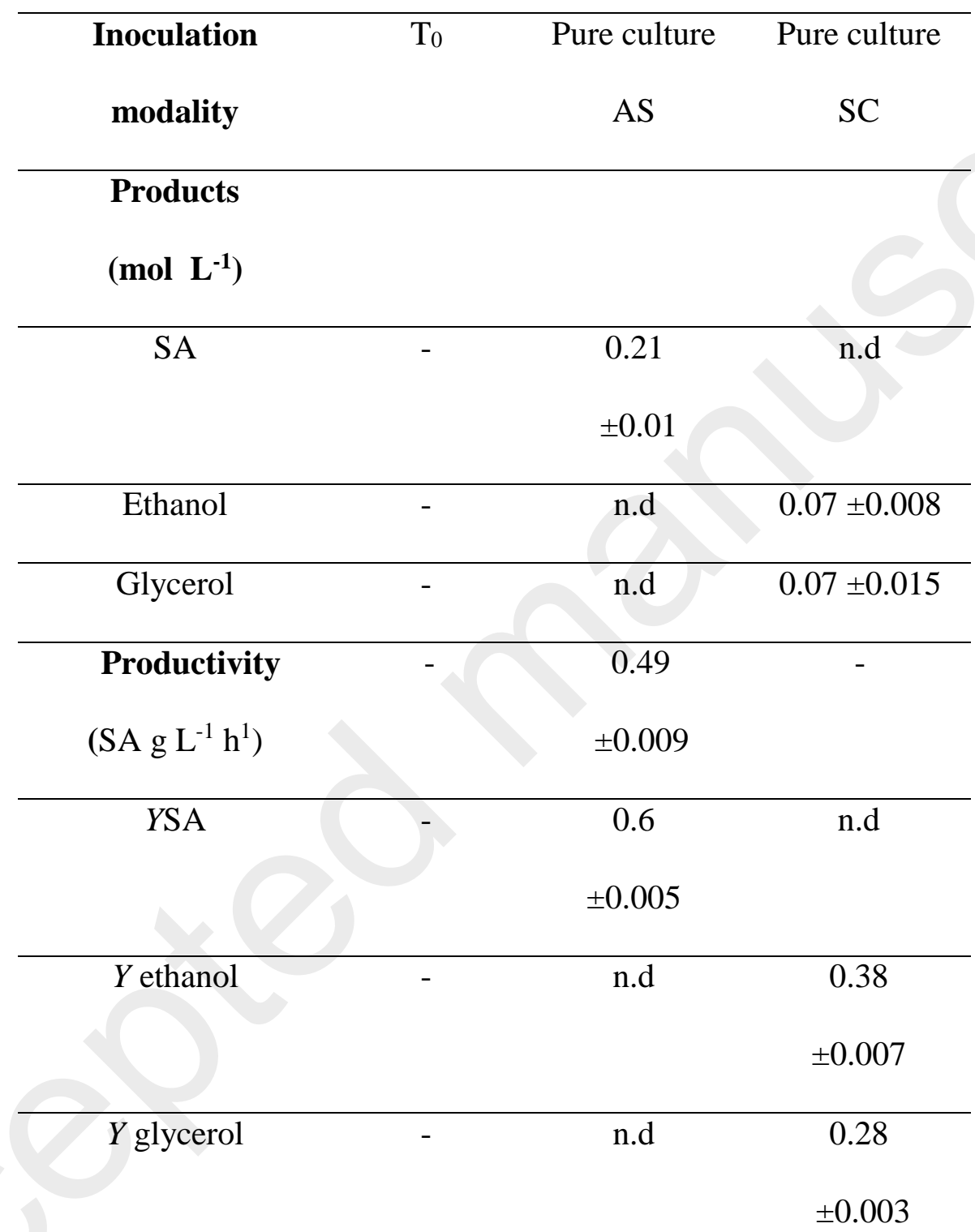

AS: A. Succinogenes, SC: S. cerevisiae, n.d. none detected; Y: yield mol-C products/ mol-C sugars 
Table 2. Influence of the mode of inoculation on the fermentation profile at the end of fermentation time (96h). Data are duplicates from two independent experiments represented as a mean \pm standard deviation.

\begin{tabular}{|c|c|c|c|c|c|c|c|}
\hline $\begin{array}{l}\text { Fermentatior } \\
\text { parameters }\end{array}$ & & & \multicolumn{2}{|c|}{ Microaerobic } & \multicolumn{3}{|c|}{ Anaerobic } \\
\hline \multirow{4}{*}{$\begin{array}{l}\text { Inoculation } \\
\text { modality }\end{array}$} & $t_{0}$ & Pure & Pure & Simulta & Sequenti & Pure & Simultan \\
\hline & & culture & culture & neous & al 48 co- & culture & eous \\
\hline & & AS & SC & Co- & culture & AS & Co- \\
\hline & & & & culture & & & culture \\
\hline \multirow[t]{2}{*}{ OD } & 0.03 & 0.39 & 1.54 & 1.05 & 1.32 & 0.36 & 0.96 \\
\hline & & \pm 0.002 & \pm 0.17 & \pm 0.06 & \pm 0.01 & \pm 0.04 & \pm 0.04 \\
\hline \multirow[t]{3}{*}{$\mathrm{pH}$} & 6.8 & 6.15 & 5.04 & 5.65 & 5.24 & 5.2 & 5.32 \\
\hline & \pm 0.0 & \pm 0.08 & \pm 0.07 & \pm 0.15 & \pm 0.08 & \pm 0.02 & \pm 0.02 \\
\hline & 2 & & & & & & \\
\hline
\end{tabular}

\begin{tabular}{cccccccc}
\hline $\begin{array}{c}\text { Substrate } \\
\left(\mathbf{m o l ~ L}^{-1}\right)\end{array}$ & & & & & & & \\
& & & & & & & \\
\hline Glucose & 0.2 & 0.11 & 0.01 & 0.04 & 0.06 & 0.02 & 0.02 \\
& \pm 0.00 & \pm 0.005 & \pm 0.000 & \pm 0.01 & \pm 0.009 & \pm 0.003 & \pm 0.001 \\
& 5 & & 1 & & & & \\
\hline Fructose & 0.2 & 0.12 & 0.014 & 0.02 & 0.10 & 0.03 & 0.02 \\
& \pm 0.00 & \pm 0.0001 & \pm 0.000 & \pm 0.003 & \pm 0.001 & \pm 0.005 & \pm 0.002 \\
& 2 & 6 & 6 & & & & \\
\hline
\end{tabular}

\section{Products}

$\left(\mathbf{m o l ~ L} \mathbf{L}^{-1}\right)$ 


\begin{tabular}{|c|c|c|c|c|c|c|c|}
\hline SA & n.d & - & - & $\begin{array}{c}0.09 \\
\pm 0.007\end{array}$ & $\begin{array}{c}0.12 \\
\pm 0.0006\end{array}$ & $\begin{array}{c}0.3 \\
\pm 0.01\end{array}$ & $\begin{array}{c}0.17 \\
\pm 0.003\end{array}$ \\
\hline Ethanol & n.d & - & $\begin{array}{r}0.147 \\
\pm 0.005\end{array}$ & $\begin{array}{c}0.07 \\
\pm 0.003\end{array}$ & $\begin{array}{c}0.071 \\
\pm 0.0007\end{array}$ & - & $\begin{array}{r}0.06 \\
\pm 0.01\end{array}$ \\
\hline Glycerol & n.d & - & $\begin{array}{c}0.025 \\
\pm 0.0005\end{array}$ & $\begin{array}{c}0.02 \\
\pm 0.002\end{array}$ & $\begin{array}{r}0.013 \\
\pm 0.007\end{array}$ & - & $\begin{array}{c}0.04 \\
\pm 0.001\end{array}$ \\
\hline $\begin{array}{l}\text { Productivit } \\
\mathbf{y} \\
\left(\text { SA g L }{ }^{-1}\right. \\
\left.\quad h^{1}\right)\end{array}$ & - & - & - & $\begin{array}{c}0.11 \\
\pm 0.008\end{array}$ & $\begin{array}{c}0.14 \\
\pm 0.0008\end{array}$ & $\begin{array}{c}0.3 \\
\pm 0.005\end{array}$ & $\begin{array}{c}0.20 \\
\pm 0.004\end{array}$ \\
\hline$Y \mathrm{SA}$ & - & - & - & $\begin{array}{c}0.41 \\
\pm 0.007\end{array}$ & $\begin{array}{r}0.34 \\
\pm 0.002\end{array}$ & $\begin{array}{r}0.84 \\
\pm 0.01\end{array}$ & $\begin{array}{c}0.44 \\
\pm 0.003\end{array}$ \\
\hline$Y$ ethanol & - & - & $\begin{array}{r}0.51 \\
\pm 0.003\end{array}$ & $\begin{array}{c}0.41 \\
\pm 0.006\end{array}$ & $\begin{array}{c}0.26 \\
\pm 0.005\end{array}$ & - & $\begin{array}{l}0.19 \\
\pm 0.01\end{array}$ \\
\hline$Y$ glycerol & - & - & $\begin{array}{c}0.06 \\
\pm 0.002\end{array}$ & $\begin{array}{c}0.08 \\
\pm 0.002\end{array}$ & $\begin{array}{c}0.02 \\
\pm 0.003\end{array}$ & - & $\begin{array}{l}0.13 \\
\pm 0.01\end{array}$ \\
\hline
\end{tabular}

AS: A. Succinogenes, SC: S. cerevisiae, n.d. none detected; Y: yield mol-C products/ mol-C sugars 
Table 3. Final parameter values ( $96 \mathrm{~h}$ culture time) during single cultures and co-culture of $A$. succinogenes and S. cerevisiae at two different temperatures. Data are duplicates from two independent experiments represented as a mean \pm standard deviation.

\begin{tabular}{|c|c|c|c|c|c|c|c|c|}
\hline $\mathrm{T}^{\circ} \mathrm{C}$ & \multicolumn{4}{|c|}{28} & \multicolumn{4}{|c|}{37} \\
\hline Inoculat & Pure & Pure & Co- & Sequen & Pure & Pure & Co- & Sequenti \\
\hline ion & cultur & cultur & culture & tial 48 & culture & culture & culture & al $48 \mathrm{~h}$ \\
\hline Modalit & e AS & e SC & & h co- & AS & $\mathrm{SC}$ & & co- \\
\hline $\mathrm{y}$ & & & & culture & & & & culture \\
\hline OD & 0.09 & 1.2 & 0.38 & 0.47 & 0.13 & $0.32 \pm 0$ & 0.36 & 0.42 \\
\hline & \pm 0.00 & \pm 0.2 & \pm 0.02 & \pm 0.03 & \pm 0.007 & .05 & \pm 0.04 & \pm 0.03 \\
\hline & 2 & & & & & & & \\
\hline $\mathrm{pH}$ & 5.9 & 4.3 & 5.2 & 5.4 & 5.7 & 4.7 & 5.5 & $4.8 \pm 0.4$ \\
\hline & \pm 0.2 & \pm 0.4 & \pm 0.05 & \pm 0.02 & \pm 0.04 & \pm 0.02 & \pm 0.09 & \\
\hline
\end{tabular}

\section{Substrate (mole $\left.\mathbf{L}^{-1}\right)$}

\begin{tabular}{ccccccccc}
\hline Glucose & 0.08 & 0.02 & 0.06 & 0.08 & 0.05 & 0.07 & 0.04 & 0.006 \\
& \pm 0.00 & \pm 0.00 & \pm 0.004 & \pm 0.001 & \pm 0.004 & \pm 0.02 & \pm 0.009 & \pm 0.0001 \\
& 5 & 7 & & & & & & \\
\hline Fructos & 0.13 & 0.03 & 0.07 & 0.13 & 0.06 & 0.1 & 0.06 & 0.008 \\
$\mathrm{e}$ & \pm 0.00 & \pm 0.00 & \pm 0.006 & \pm 0.000 & \pm 0.007 & \pm 0.001 & \pm 0.004 & \pm 0.0009 \\
& 3 & 5 & & 2 & & & &
\end{tabular}

\section{Product (mole $\mathrm{L}^{-1}$ )}

\begin{tabular}{|c|c|c|c|c|c|c|c|c|}
\hline \multirow[t]{2}{*}{ Ethanol } & n.d & 0.1 & 0.08 & 0.06 & n.d & 0.04 & 0.05 & 0.06 \\
\hline & & \pm 0.01 & \pm 0.006 & \pm 0.004 & & \pm 0.007 & \pm 0.01 & \pm 0.003 \\
\hline
\end{tabular}




\begin{tabular}{|c|c|c|c|c|c|c|c|c|}
\hline SA & $\begin{array}{r}0.07 \\
\pm 0.01\end{array}$ & n.d & $\begin{array}{c}0.09 \\
\pm 0.003\end{array}$ & n.d & $\begin{array}{c}0.3 \\
\pm 0.02\end{array}$ & n.d & $\begin{array}{r}0.22 \\
\pm 0.01\end{array}$ & $\begin{array}{c}0.27 \\
\pm 0.007\end{array}$ \\
\hline Glycero & n.d & 0.03 & 0.06 & 0.06 & n.d & 0.02 & 0.03 & 0.005 \\
\hline 1 & & \pm 0.00 & \pm 0.007 & \pm 0.001 & & \pm 0.009 & \pm 0.005 & \pm 0.0008 \\
\hline
\end{tabular}

AS: A. Succinogenes, SC: S. cerevisiae, n.d. non detected, pure culture in this experiment were performed in anaerobic fermentation. 
Table 4. A selection of microbial co-cultures, their mode cultures, substrates and their products. GMO genetically engineered organism.

\begin{tabular}{|c|c|c|c|c|}
\hline Co-culture & mode & substrate & Products & Ref \\
\hline $\begin{array}{l}\text { Careboxydothermus } \\
\text { hydrogenoformans and } \\
\text { Methanothermobacter } \\
\text { thermoautotrophicus }\end{array}$ & Continuous & $\mathrm{CO}, \mathrm{H}_{2}$ & $\mathrm{H}_{2} / \mathrm{CO}_{2}$, methane & [44] \\
\hline $\begin{array}{l}\text { Clostridiumljungdahlii } \\
\text { and Clostridium kluyveri }\end{array}$ & Fed batch & $\begin{array}{l}\mathrm{CO} / \\
\mathrm{H}_{2} / \mathrm{CO}_{2}\end{array}$ & $\begin{array}{l}\text { Acetate/ ethanol, } \\
\text { C4-C8 fatty acid } \\
\text { and alcohols }\end{array}$ & [45] \\
\hline $\begin{array}{l}\text { Clostridium autoethanogenum } \\
\text { and Clostridium kluyveri }\end{array}$ & $\begin{array}{l}\text { Continuous } \\
\text { chemostat }\end{array}$ & $\begin{array}{l}\mathrm{CO} / \\
\mathrm{H}_{2} / \mathrm{CO}_{2}\end{array}$ & $\begin{array}{l}\text { Acetate/ ethanol, } \\
\text { C4-C8 fatty acid } \\
\text { and alcohols }\end{array}$ & [46] \\
\hline $\begin{array}{l}\text { A. succinogenes and } \\
\text { S. cerevisiae }\end{array}$ & Batch & $\begin{array}{l}\text { Glucose, } \\
\text { Fructose }\end{array}$ & $\begin{array}{l}\text { Succinate, } \\
\text { ethanol, glycerol }\end{array}$ & $\begin{array}{l}\text { This } \\
\text { study }\end{array}$ \\
\hline $\begin{array}{l}\text { Escherichia coli } \\
\text { and Methanobacterium } \\
\text { formicicum }\end{array}$ & Batch & Glycerol & succinate & [42] \\
\hline $\begin{array}{l}\text { Geobacter sulfurreducens and } \\
\text { Clostridium pasteurianum }\end{array}$ & Batch & $\begin{array}{l}\text { Glycerol, } \\
\text { acetate }\end{array}$ & $\begin{array}{l}\text { propanediol, } \\
\text { butyrate }\end{array}$ & [47] \\
\hline $\begin{array}{l}\text { Clostridium } \\
\text { ljungdahlii and Clostridium } \\
\text { acetobutylicum }\end{array}$ & Batch & Glucose & $\begin{array}{l}\text { 2,3-butanediol, } \\
\text { isopropanol }\end{array}$ & [43] \\
\hline $\begin{array}{l}\text { Clostridium acetobutylicum and } \\
\text { Clostridium cellulolyticum }\end{array}$ & Batch & Cellulose & $\begin{array}{l}\text { Pyruvate, } \\
\text { butanol }\end{array}$ & [48] \\
\hline $\begin{array}{l}\text { Escherichia } \\
\text { coli and Saccharomyces } \\
\text { cerevisiae (GMO) }\end{array}$ & Fed batch & Xylose & $\begin{array}{l}\text { oxygenated } \\
\text { taxanes, } \\
\text { sesquiterpenes, } \\
\text { acetate }\end{array}$ & [49] \\
\hline
\end{tabular}

